\title{
DESENVOLVIMENTO DE COMPETÊNCIAS NA ÁREA DE TECNOLOGIA PARA ESTUDANTES DE ENSINO MÉDIO
}

\author{
Jalberth Fernandes de Araújo ${ }^{1}$ \\ https://orcid.org/0000-0003-3468-3009 \\ JÉssica Ferreira de Matos ${ }^{2}$ \\ https://orcid.org/0000-0002-5282-2060 \\ Joyce Vanessa Morais Rodrigues 3 \\ https://orcid.org/0000-0002-0078-8016 \\ Kaio Vítor Gonçalves Freitas ${ }^{4}$ \\ https://orcid.org/ 0000-0001-6653-8290 \\ Marya Marlly Vieira Formiga ${ }^{5}$ \\ https://orcid.org/0000-0001-7257-3236
}

Resumo: Neste artigo são apresentados resultados da execução do projeto de extensão intitulado Desenvolvimento de Competências na Área de Tecnologia para Estudantes do Ensino Médio. As competências foram desenvolvidas a partir de conhecimentos práticos sobre programação e eletrônica. O projeto foi desenvolvido em uma escola pública do município de Campina Grande, Paraíba, por estudantes do curso de Engenharia Elétrica da Universidade Federal de

1 Jalberth Fernandes de Araújo, professor, Engenharia Elétrica, doutorado e pós-doutorado em Engenharia Elétrica pela UFCG, Universidade Federal de Campina Grande. E-mail: jalberth@dee.ufcg. edu.br

2 Jéssica Ferreira de Matos, graduanda, Engenharia Elétrica, Universidade Federal de Campina Grande. E-mail: jessica.matos@ee.ufcg.edu.br

3 Joyce Vanessa Morais Rodrigues, graduanda, Engenharia Elétrica, Universidade Federal de Campina Grande. E-mail: joyce.rodrigues@ee.ufcg.edu.br

4 Kaio Vítor Gonçalves Freitas, graduando, Engenharia Elétrica, Universidade Federal de Campina Grande. E-mail: kaio.freitas@ee.ufcg.edu.br

5 Marya Marlly Vieira Formiga, graduanda, Engenharia Elétrica, Universidade Federal de Campina Grande. E-mail: marya.marlly@ee.ufcg.edu.br 
Campina Grande. De acordo com os resultados obtidos, foi possível constatar que os estudantes beneficiados desenvolveram não só as competências na área de tecnologia, mas também outras habilidades, tais como: criatividade, resiliência e mentalidade empreendedora.

Palavras-chave: Extensão. Ensino. Tecnologia. Competências.

\begin{abstract}
This article presents results of execution the extension project entitled Development of Competences in the Technology Area for High School Students. The competences were developed from practical knowledge about programming and electronics. The project was developed in a public school in the city of Campina Grande, Paraíba, by students of the Electrical Engineering course of the Federal University of Campina Grande. According to the results obtained, it was possible to verify that the students benefited developed not only the competencies in the area of technology, but also other abilities, such as: creativity, resilience and entrepreneurial mentality.
\end{abstract}

Keywords: Extension. Teaching. Technology. Competencies.

Resumen: En este artículo se presentan resultados de la ejecución del proyecto de extensión titulado Desarrollo de Competencias en el Área de Tecnología para Estudiantes de la Enseñanza Media. Las competencias se desarrollaron a partir de conocimientos prácticos sobre programación y electrónica. El proyecto fue desarrollado en una escuela pública del municipio de Campina Grande, Paraíba, por estudiantes del curso de Ingeniería Eléctrica de la Universidad Federal de Campina Grande. De acuerdo con los resultados obtenidos, fue posible constatar que los estudiantes beneficiados desarrollaron no sólo las competencias en el área de tecnología, sino también otras habilidades, tales como: creatividad, resiliencia y mentalidad emprendedora.

Palabras clave: Extensión. Educación. Tecnología. Habilidades.

Submetido em: 02/12/2018

Aceito em: 21/12/2018.

\title{
INTRODUÇÃO
}

O grande desafio, nos dias atuais, do sistema educacional brasileiro é a motivação dos estudantes com relação ao que é estudado. Segundo Alexandre Costa da Silva, a motivação dos alunos cai ao longo dos anos pelo acúmulo de dúvidas desde as séries iniciais e pelo sentimento de incapacidade ao final destas. Diante deste cenário, as possibilidades de projetos que possam auxiliar na motivação desses estudantes são várias e uma das mais eficazes é a extensão universitária. A extensão universitária tem o papel fundamental de conectar a Universidade à comunidade. Essa conexão pode ser feita a partir de projetos de extensão, que representam o conjunto de ações processuais contínuas, de caráter educativo, social, cultural ou tecnológico, 
que tem por objetivo promover a ação transformadora entre a universidade e outros setores da sociedade.

As atividades realizadas nos projetos de extensão possibilitam estimular os participantes no desenvolvimento de sua criatividade, principalmente na busca da socialização dos saberes, aprimorando o seu processo formativo de profissional enquanto cidadão. A partir do desenvolvimento da criatividade e aprimoramento do processo formativo do profissional enquanto cidadão, priorizando as áreas de demandas de relevância social e melhorando as condições de vida das comunidades beneficiadas pelo projeto. Dentre as áreas de demandas de relevância social que mais vem crescendo atualmente, pode-se destacar a área de tecnologia.

Atualmente, existe uma grande preocupação com a falta de engenheiros no Brasil. Segundo estudo do Instituto de Pesquisa Econômica Aplicada (Ipea), o Brasil pode sofrer, a partir de 2020, um “apagão de engenheiros”. Devido ao déficit de engenheiros no Brasil, para que a demanda por profissionais de engenharia seja suprida, seria necessário formar 60 mil engenheiros por ano, mas apenas 32 mil são formados a cada ano, conforme estudo do Conselho Nacional da Indústria (CNI).

Para diminuir a evasão e motivar os estudantes a cursarem engenharia, ou cursos da área de tecnologia, é de fundamental importância a implementação de projetos de extensão como este. Neste projeto de extensão é proposto que, a partir de conhecimentos práticos sobre arduino e eletrônica, sejam desenvolvidas, em estudantes do ensino médio, competências na área de tecnologia.

Além de desenvolver competências na área de tecnologia para os estudantes de ensino médio, a realização deste projeto de extensão capacita também os estudantes de graduação que participam do projeto, uma vez que ele é mediado por estudantes de graduação.

\section{METODOLOGIA}

Com o intuito de alcançar os objetivos do Projeto de Extensão, o coordenador e os 05 estudantes do Curso de Graduação em Engenharia Elétrica planejaram todas as atividades que foram realizadas durante o período de vigência do projeto. As atividades foram planejadas por meio de reuniões semanais que foram estabelecidas como forma de sistematização para uma melhor 
condução do projeto. Sabendo disso, os estudantes de graduação desenvolveram, sob a devida orientação, as seguintes atividades:

- Realização de treinamentos sobre conhecimentos práticos em eletrônica;

- Realização de treinamentos sobre o uso dos principais dispositivos eletrônicos;

- Realização de treinamentos sobre o uso de equipamentos para montagem de módulos de eletrônica básica;

- Montagem de módulos de eletrônica básica;

- Realização de treinamentos sobre programação em plataformas microcontroladas;

As atividades descritas acima foram iniciadas com uma palestra do coordenador do projeto, professor Jalberth Fernandes de Araujo, com o tema "Perfil do Profissional de 2020". Após a palestra, as atividades foram subdivididas em dois treinamentos para desenvolvimentos de competências: Eletrônica Básica e Programação da Plataforma Microcontrolada (Arduino).

Figura 1: Coordenador do Projeto de Extensão em sua Primeira palestra soBRE O TEMA: "PeRFIL do PROFISSIONAL DE 2020"

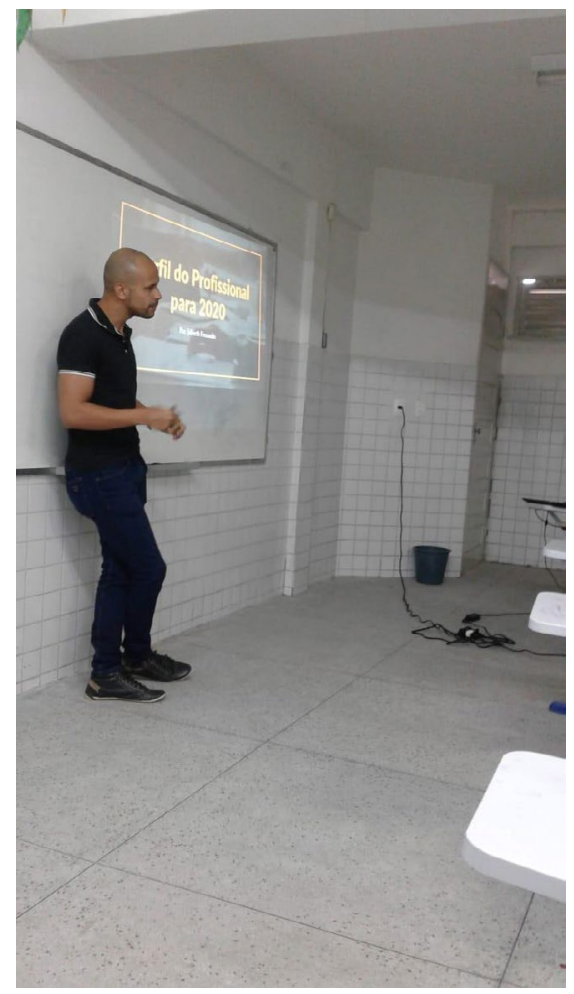

CRÉditos: JOYCE VANESSA MORAIS ROdRIGUES 


\section{FiguRA 2: ALUNOS DURANTE A PRIMEIRA PALESTRA}

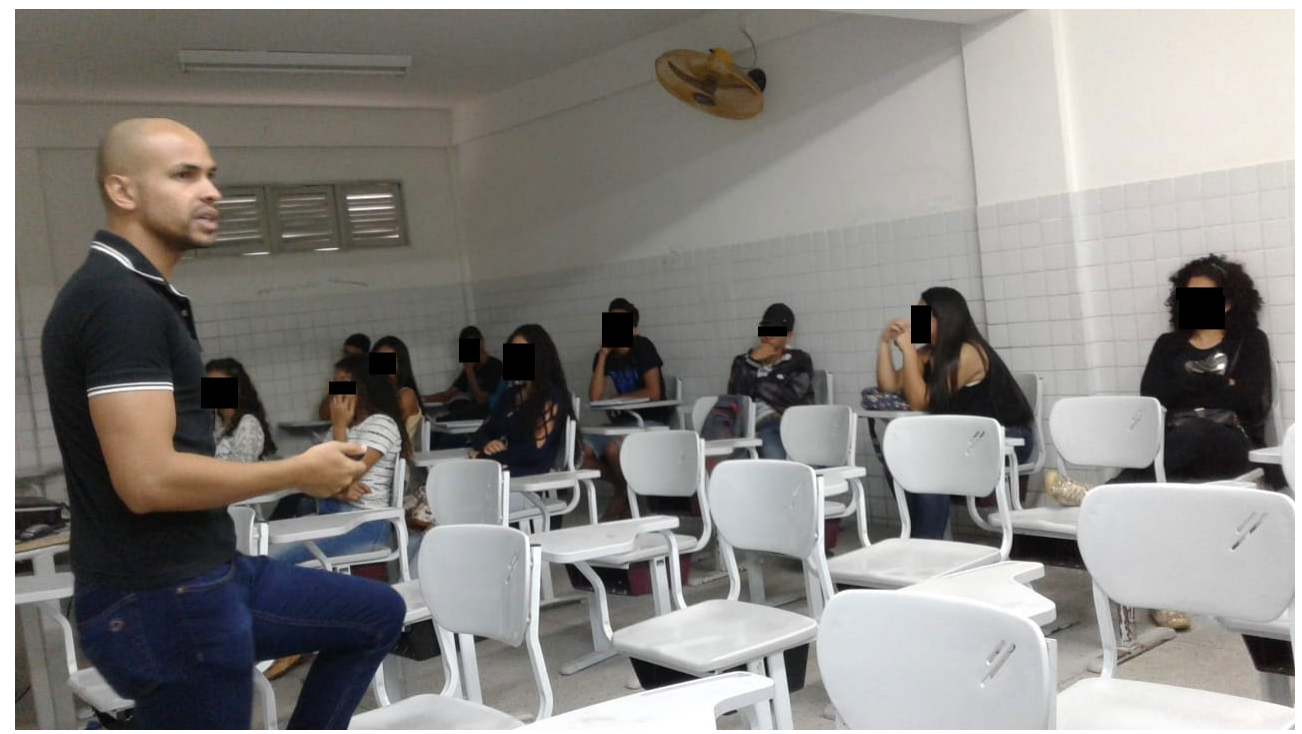

Figura 3: CONTINUAÇÃo de ALUNOS DURANTE A PRIMEIRA PALESTRA.

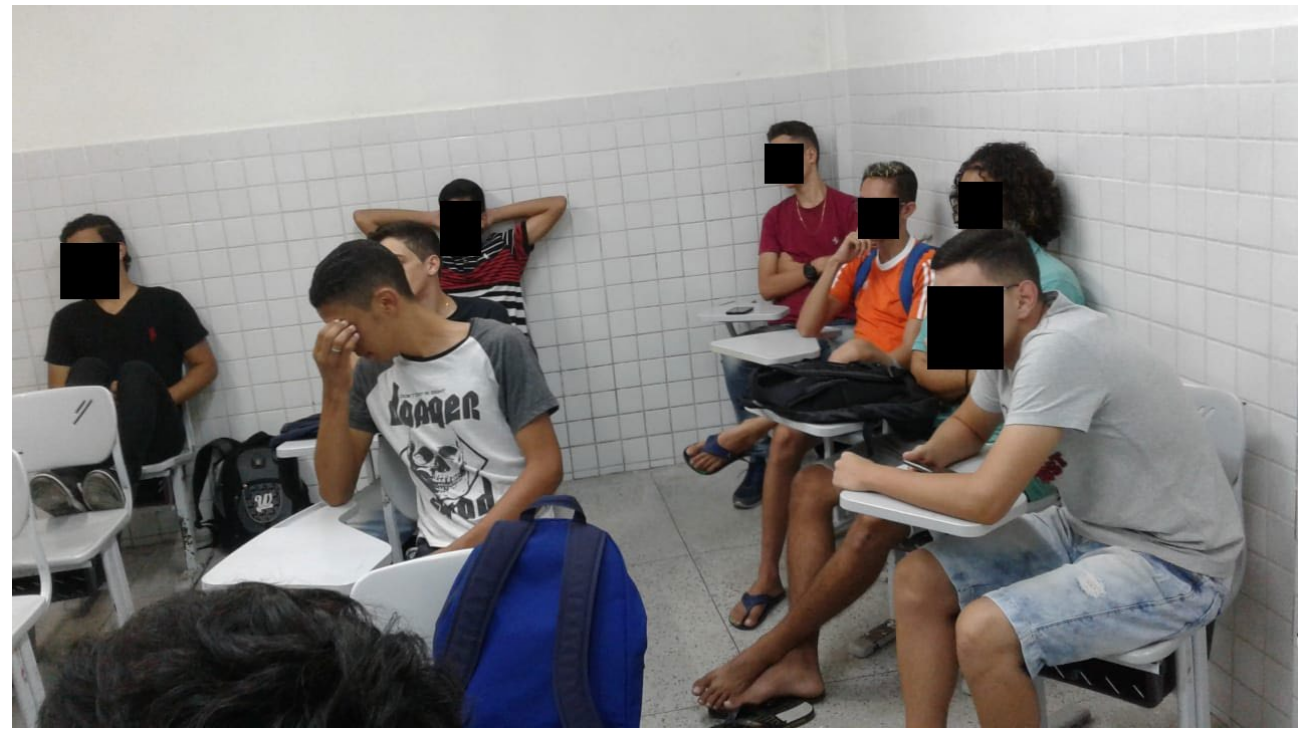

CRÉditos: JOYCE VANESSA MORAIS ROdRIGUeS

Os alunos de ensino médio que tiveram interesse no Projeto de Extensão foram divididos em duas turmas estrategicamente, para que cada dupla de graduandos ficasse responsável por uma única turma, tendo em vista que o projeto era formado por 05 participantes da graduação, e um dos bolsistas ficasse responsável por todo planejamento estratégico que garantisse a continuação e qualidade das aulas: ementa, slides, separação de materiais, formulação de atividades e projetos. 
Os treinamentos foram iniciados à partir da teoria básica sobre os principais dispositivos eletrônicos (SEDRA; SMITH, 2007; RAZAVI, 2010), pois eram de fundamental importância para o andamento do projeto. Os treinamentos foram instruídos por meio de gincanas, para induzir a perda da fronteira entre treinador e aluno, fronteira muitas vezes criada dentro de sala de aula, impedindo uma melhor compreensão sobre o assunto abordado. $\mathrm{Na}$ sequência, foi elaborado o treinamento sobre eletrônica básica, que tinha a prática como foco principal. $\mathrm{O}$ treinamento foi executado no Laboratório de Informática da Escola Normal Estadual Padre Emídio Viana Correia. Como o material para realização das atividades experimentais era limitado, o público alvo foi dividido em duplas para que fosse possível o conhecimento prático satisfatório no decorrer do treinamento.

Após o treinamento sobre Eletrônica Básica, foi iniciado o treinamento sobre Programação na Plataforma Microcontrolada Arduino. O treinamento foi ministrado também no Laboratório de Informática da escola. No treinamento, os Arduinos eram previamente configurados pelos alunos de graduação participantes do projeto. A utilização do Arduino permitiu o desenvolvimento de projetos que foram apresentados como produto final do Projeto de Extensão em conjunto com as habilidades e competências profissionais, introduzidas na palestra sobre as competências esperadas pelo profissional de 2020 introduzida pelo professor Jalberth.

FigURA 4: LABORATÓRIO DE INFORMÁTICA COM O SOFTWARE DA PLATAFORMA ARDUINO INSTALADOS EM CADA COMPUTADOR.

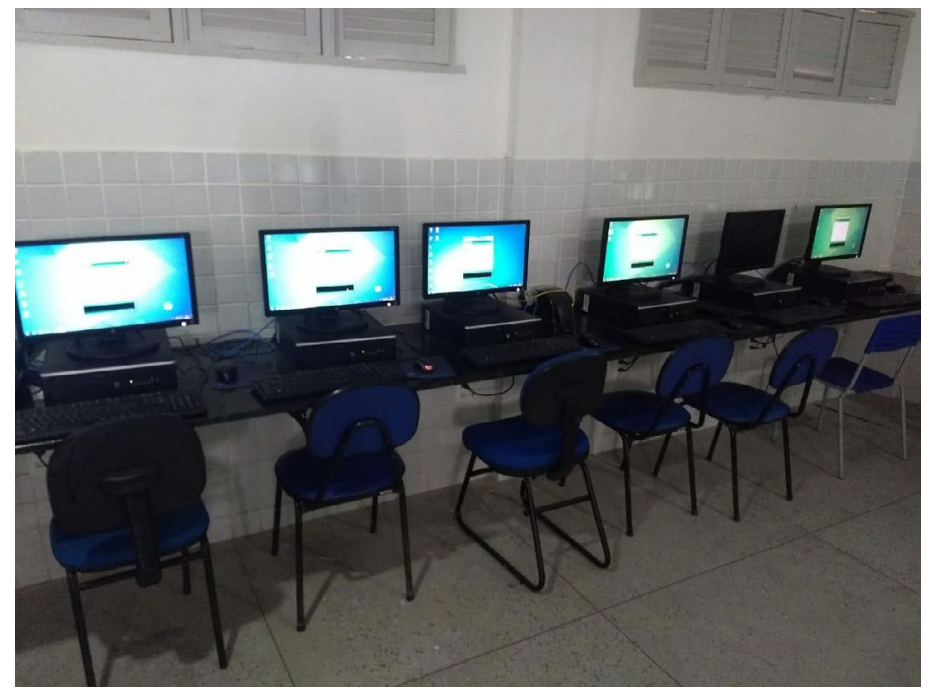

CRÉditos: KaIo Vítor Gonçalves Freitas 
Assim, com os estudantes de graduação devidamente orientados, foi possível desenvolver as atividades com o intuito de capacitar os estudantes do ensino médio com os conhecimentos práticos sobre eletrônica básica, programação e habilidades do século 21. Também, os estudantes de graduação beneficiados tiveram uma participação ativa em todas as atividades que foram desenvolvidas neste projeto, com o intuito de aprender e adquirir a partir da experiência prática, os conhecimentos práticos sobre eletrônica e programação e, consequentemente, as competências na área de tecnologia, que é o objetivo principal deste Projeto de Extensão.

\section{ATIVIDADES DESENVOLVIDAS}

\subsection{Planejamento das Atividades (14/05/2018 a 14/07/2017)}

No mês de maio, houve o início da vigência do projeto com a primeira reunião com o orientador, e consequentes reuniões entre os membros com o foco de organizar o início das atividades, com discussões sobre a gestão do dinheiro que havia sobrado da vigência passada do projeto, sendo usado para o ressarcimento de passagens de ônibus e materiais para os participantes do grupo e o resto guardado para ser usado no projeto atual.

Apesar disso, na sexta-feira (18/05/2018), três integrantes que não possuíam aulas na Universidade ou trabalho no período da tarde, foram até a escola Normal Estadual Padre Emídio Viana Correia, onde foi encontrado o professor Agnaldo que agiu como guia dos integrantes pelo colégio, mostrando-os o Laboratório de Informática, onde foram executadas as aulas do projeto. Havia 18 computadores funcionando no laboratório, os quais possuíam acesso à internet, o que facilitou o desenvolvimento das atividades.

No mês de junho, houve o planejamento das atividades referentes ao desenvolvimento do projeto de extensão ao longo do ano de 2018. Por meio de reuniões presenciais e virtuais com os membros do projeto, foi discutida e acordada a elaboração da ementa com os conteúdos que seriam transmitidos aos alunos de Ensino Médio. Também foi agendada a visita à escola beneficiada para que pudesse ser feita a apresentação dos projetos aos estudantes e também feita a seleção dos estudantes beneficiados, que se deu por meio do preenchimento de formulários de inscrição elaborados pelos graduandos.

Assim sendo, a escola recebeu a visita dos alunos de graduação no dia 13 de Junho de 2018 para a divulgação do projeto de extensão da UFCG e, 
consequentemente, a inscrição dos estudantes de ensino Médio interessados em participar.

Ao final, percebeu-se que 35 alunos demonstraram interesse em participar do projeto e, como o número de inscritos foi significativo, ficou decidido que fosse realizada uma divisão de duas turmas para que o aprendizado se tornasse mais efetivo.

Além do mais, por motivos de compatibilidade de horários, os treinamentos foram realizados semanalmente aos sábados com duração de 02 horas e se iniciaram no Laboratório de Informática da referida escola no dia 14 de Julho de 2018, que foi a data mais adequada de acordo com o calendário escolar vigente.

Por fim, o último passo dado foi a criação da ementa do curso, que consiste em 02 aulas sobre eletrônica analógica básica e 08 aulas de programação com a plataforma Arduino, com grande foco nas aplicações, pois foi percebido, na experiência da vigência anterior, que os alunos ficam mais motivados a comparecer as aulas quando passam mais tempo no experimento prático do assunto.

\subsection{Eletrônica básica (21/07/2018 a 11/08/2018)}

Inicialmente, foram feitas as entrevistas individuais com os alunos no próprio Laboratório de Informática da escola antes da aula, como planejado, havendo a apresentação do conteúdo da aula em sequência.

A primeira aula com os integrantes do projeto foi sobre eletrônica com conceitos básicos de tensão, corrente, resistência e uso de componentes que seriam necessários no estudo da plataforma Arduino, como protoboard, resistores, jumpers e potenciômetros, além do uso de multímetros cedidos pelo Laboratório de Instrumentação e Metrologia Científica (LIMC) para melhorar a didática no ensino sobre as grandezas elétricas básicas.

Assim, foi dada a continuidade com as aulas teóricas e práticas de acordo com a ementa elaborada entre os membros.

O projeto recebeu neste mês uma nova integrante voluntária em substituição de uma integrante que estava em processo de intercâmbio internacional. A nova integrante contribuiu com o desenvolvimento do projeto.

3.3. Programação da Plataforma Microcontrolada Arduino (25/08/2018 a 01/12/2018)

Ainda no mês de agosto, foi iniciado o treinamento do microcontrolador Arduino para que a efetivação do módulo ocorresse. As turmas estavam em 
sincronia com os conteúdos e havia presença significativa dos estudantes do ensino médio. Sendo assim, também há nos graduandos um sentimento motivacional para que as atividades continuassem progredindo a cada sábado.

De forma geral, nas aulas subsequentes, contemplou-se noções básicas de programação, formatação básica do software Arduino, hardware do Arduino, pinos de alimentação, portas digitais, pinos PWM e portas analógicas (MCROBERTS, 2011), iniciando-se com a teoria e seguindo com montagens, em que os alunos foram divididos em grupos proporcionais à quantidade de Arduinos.

Houve reuniões para que fosse repensado a questão o orçamento para transportes dos integrantes do grupo, uma vez que um deles não poderia mais usar seu carro para buscar a sua parceira de aulas em casa.

Apesar disso, foi refeita a ementa do curso considerando-se o feriado municipal do dia 08/12/2018 e os dois fins de semana em que a escola seria interditada devido às eleições. Entre os integrantes, foi decidida como a melhor saída a implementação de 03 horas de aula por fim de semana, no lugar de 02 horas, contando com o apoio de todos os alunos.

Então, notou-se sucesso com o aumento das horas de aula com o cumprimento do que foi planejado e rendimento contínuo dos alunos com os assuntos abordados.

No mês de outubro, foi dada a continuidade com as aulas teóricas e práticas de acordo com a ementa elaborada entre os membros. Ainda no referido mês, foi dada continuidade nas atividades referentes à plataforma Arduino com a inserção de uma interface gráfica que foi o LCD e, além disso, o projeto adquiriu novos componentes eletrônicos a fim de melhorar o desempenho individual e o manuseio dos estudantes de ensino médio nas montagens e nas suas experiências em aprendizagem.

Já no mês de novembro, um dos bolsistas do grupo criou arquivos com sugestões de projetos a serem feitos pelos alunos, de forma que os alunos se organizassem em 5 grupos de mesma quantidade de pessoas de acordo com o total da sala e escolhessem uma das sugestões. Assim, ao escolher o projeto, os grupos iniciaram a confecção durante a mesma aula com o auxílio dos professores utilizando os arquivos em apresentação de slides feito pelos bolsistas para cada um dos projetos, cujo conteúdo era a descrição do funcionamento de cada projeto, os materiais utilizados, o passo a passo da montagem e cada etapa de escrita do código no software da plataforma Arduino. 
No mês de dezembro, foi ensinado aos alunos o uso de sensores de temperatura e luminosidade e, por fim, foram realizadas as montagens práticas na escola com os alunos de todas as turmas juntos, para que todos os professores tivessem a oportunidade de estar presentes e dividirem seu auxílio entre os grupos. Os alunos se dividiram em 05 grupos, cujos projetos escolhidos e desenvolvidos em sala de aula foram: Piano, Indicador de Luminosidade, Interruptor, Semáforo e Protótipo de um sensor de Ré de Automóveis.

Durante as montagens, os professores orientaram os alunos primeiramente sobre o funcionamento do projeto escolhido por eles. Assim montaram o projeto na protoboard entendendo o valor de tensão em todos os nós do sistema e o sentido da corrente nas malhas para que, enfim, desenvolvessem a lógica de programação para que o circuito se comportasse da forma que é esperada por sua definição.

\section{Figura 5: Primeiro GRUPo de ALUNOS DURANTE AS AULAS DE ARDUINO.}

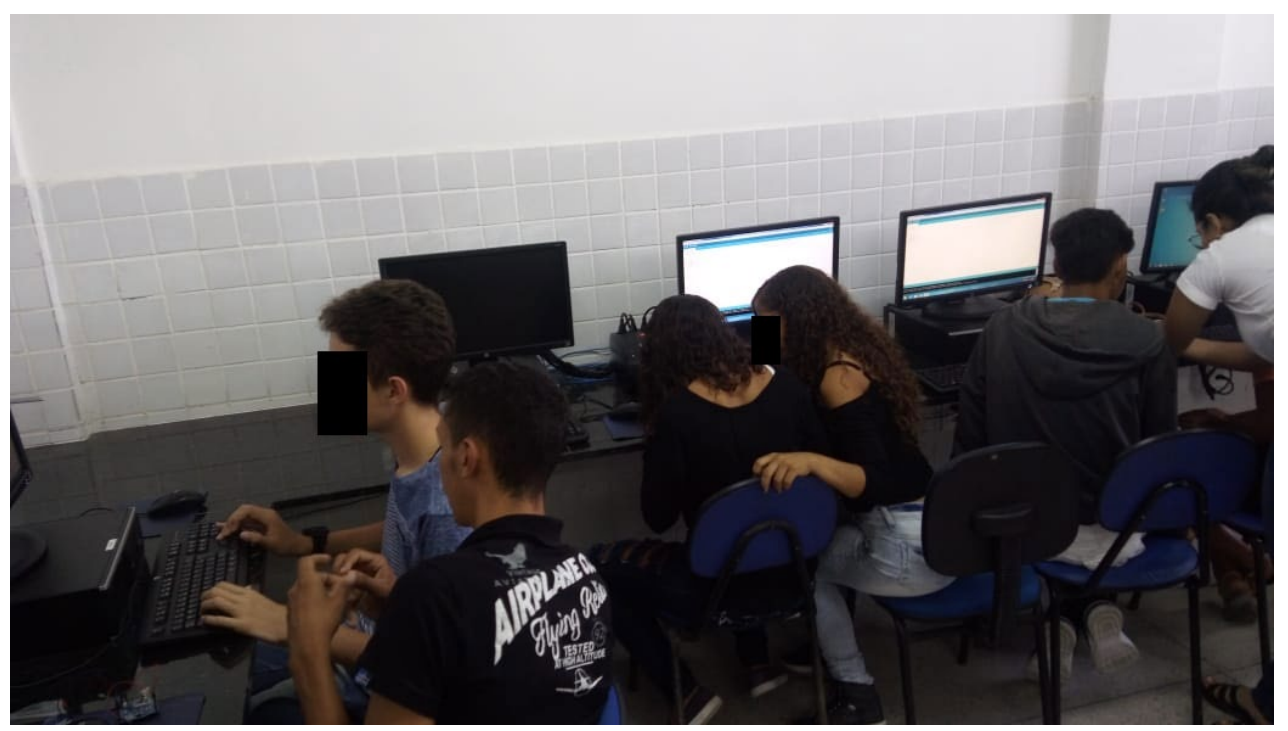

CRÉditos: MARYA MARLLY VIEIRA Formica. 
FIGURA 6: SEGUNDO GRUPO DE ALUNOS DURANTE AS AULAS DE ARDUINO.

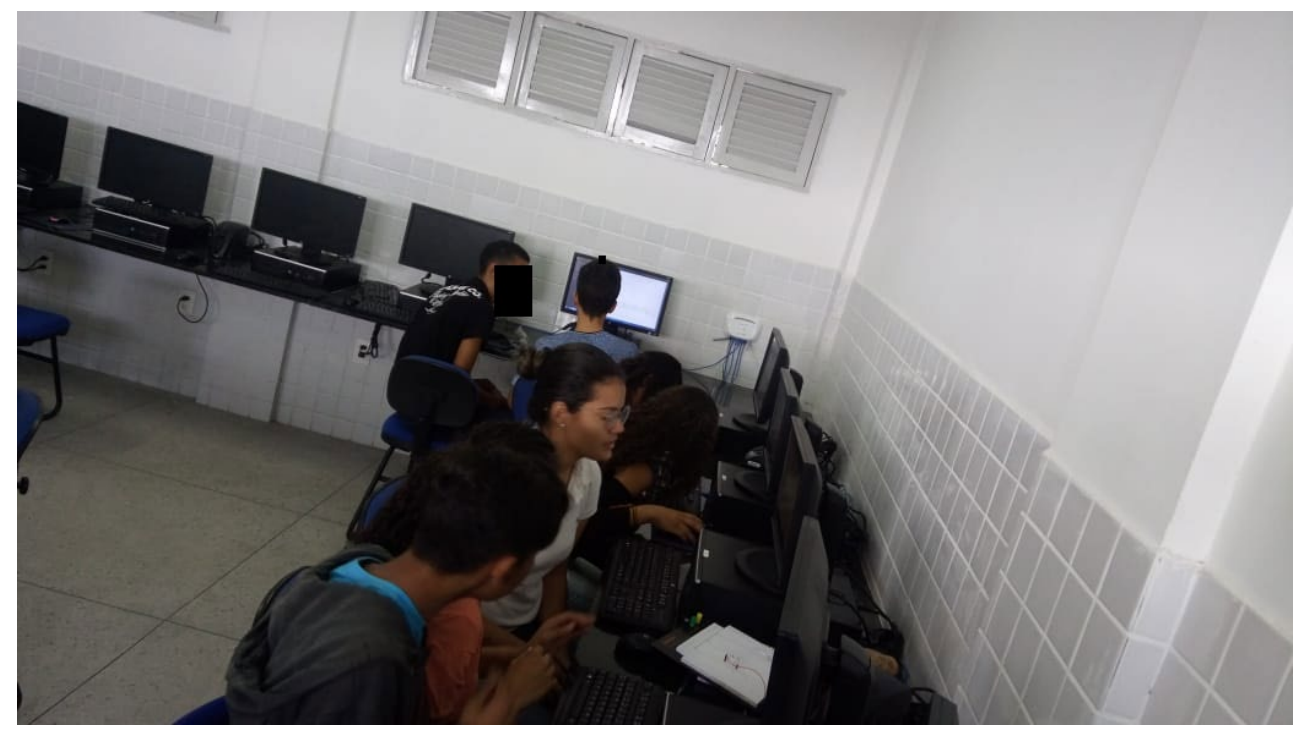

CRÉdITOS: MARYA MARLly VIEIRA FormiGa.

FIGURA 7: TERCEIRO GRUPO DE ALUNOS DURANTE AS AULAS DE ARDUINO.

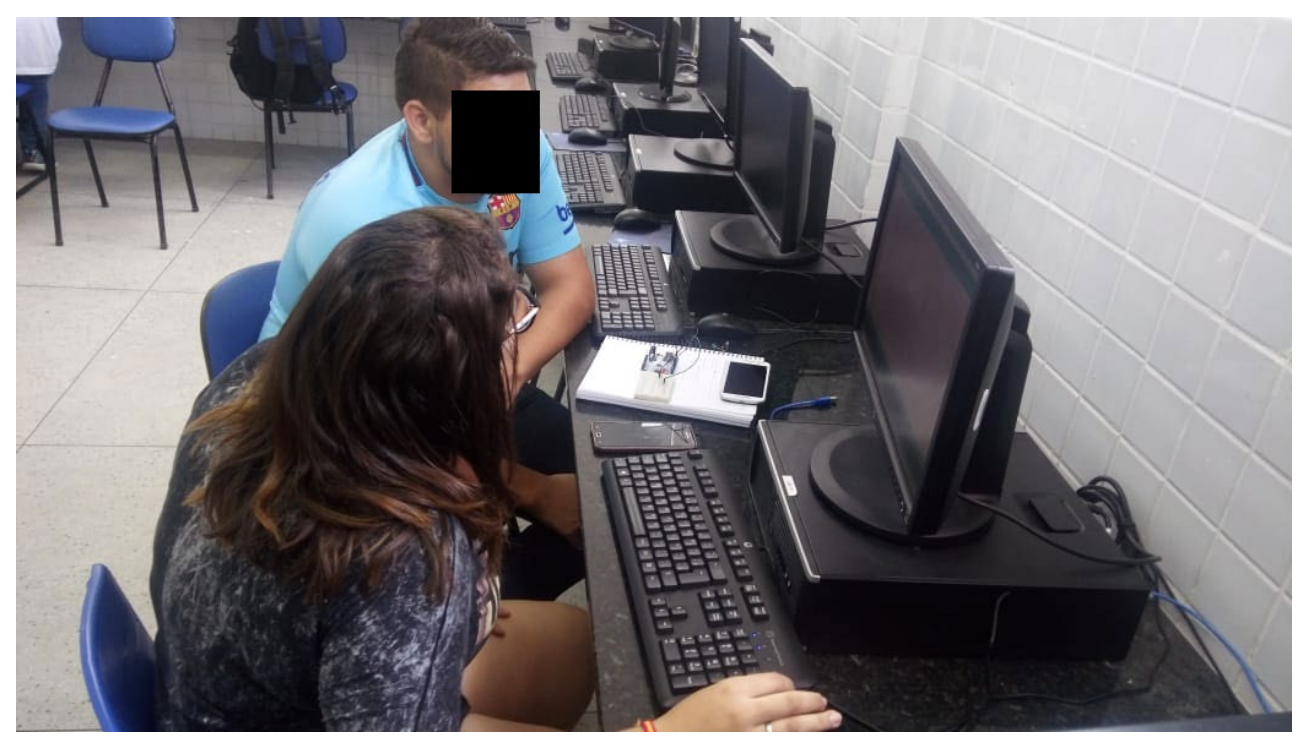

CRÉdITOS: ]ÉSSICA FERREIRA de MATOS. 
FIGURA 8: QUARTO GRUPO DE ALUNOS DURANTE AS AULAS DE ARDUINO.

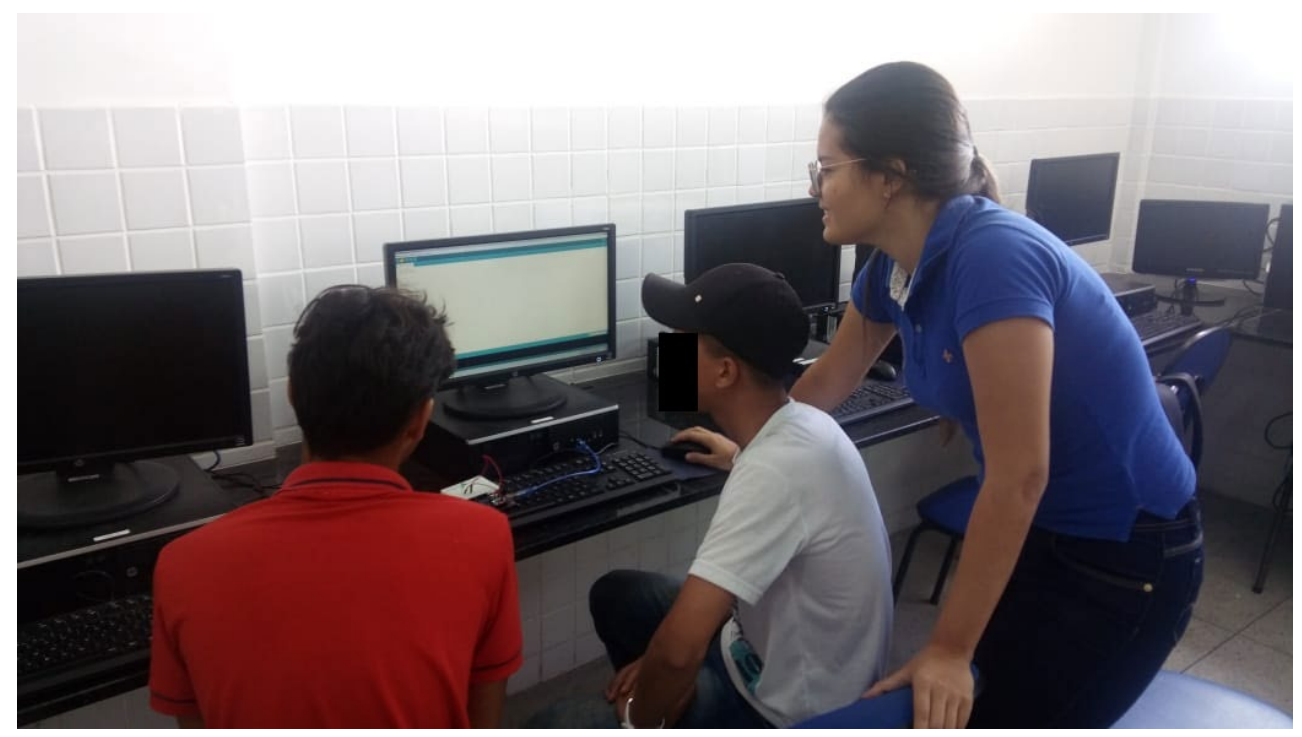

CRÉditos: JÉssica FerReIRA de Matos.

3.4. Apresentação Final - Mostra de Projetos (05/12/2018)

No dia 05/12, foi feita uma Mostra dos Projetos na escola em que os alunos levaram seus circuitos montados para exposição entre os professores, alunos e o coordenador do projeto Jalberth Fernandes de Araujo, explicando o funcionamento de seu circuito, a lógica de programação e a aplicabilidade do que foi desenvolvido no nosso dia-a-dia, desenvolvendo mais do que competências técnicas como foi almejado desde o início do projeto. 
Figura 9: Visita de alunos e professores à Mostra de Projetos.

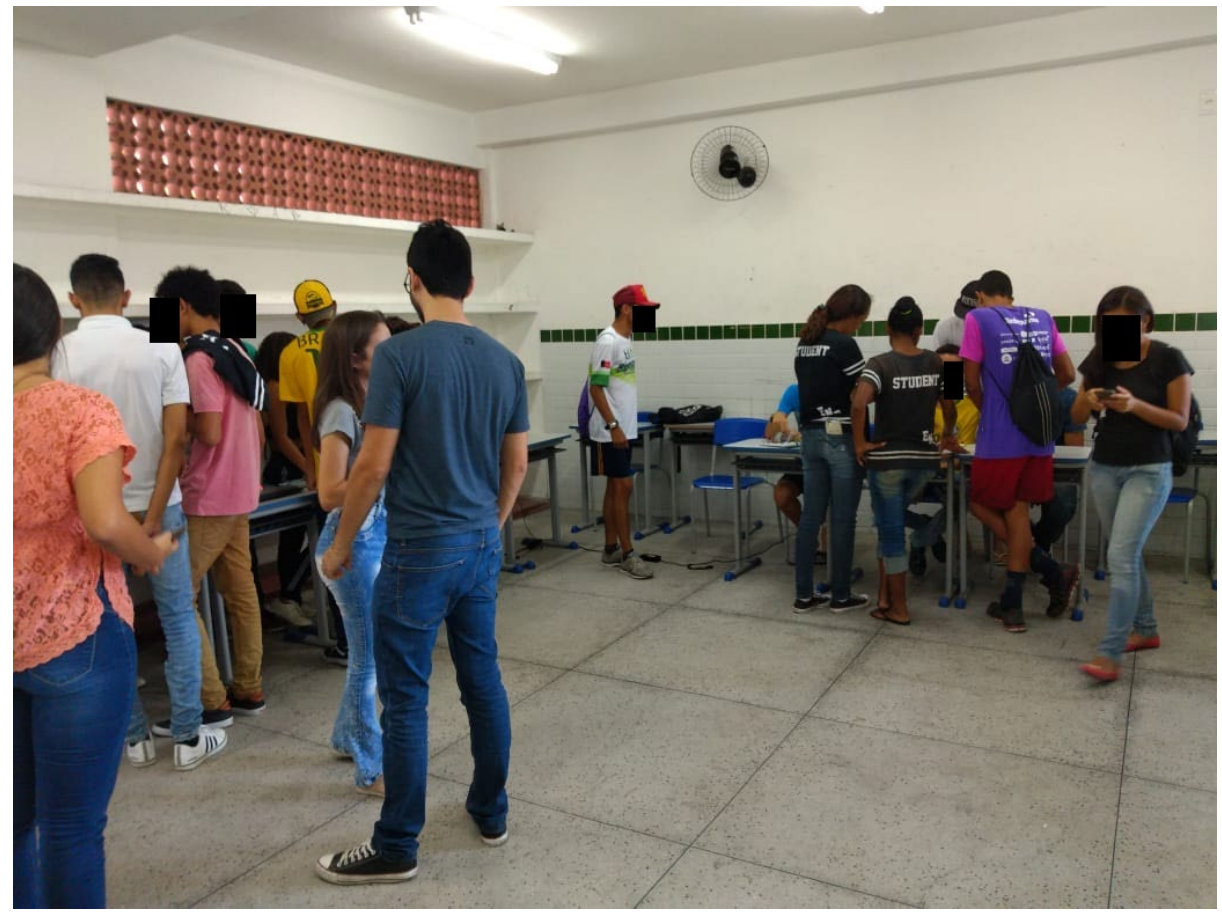

CRÉditos: JoYce VANessa Morais Rodricues.

FiguRA 10: COORDENADOR, BOLSISTAS E VOLUNTÁRIOS DO PROJETO DE EXTENSÃO DURANTE A Mostra De Projetos.

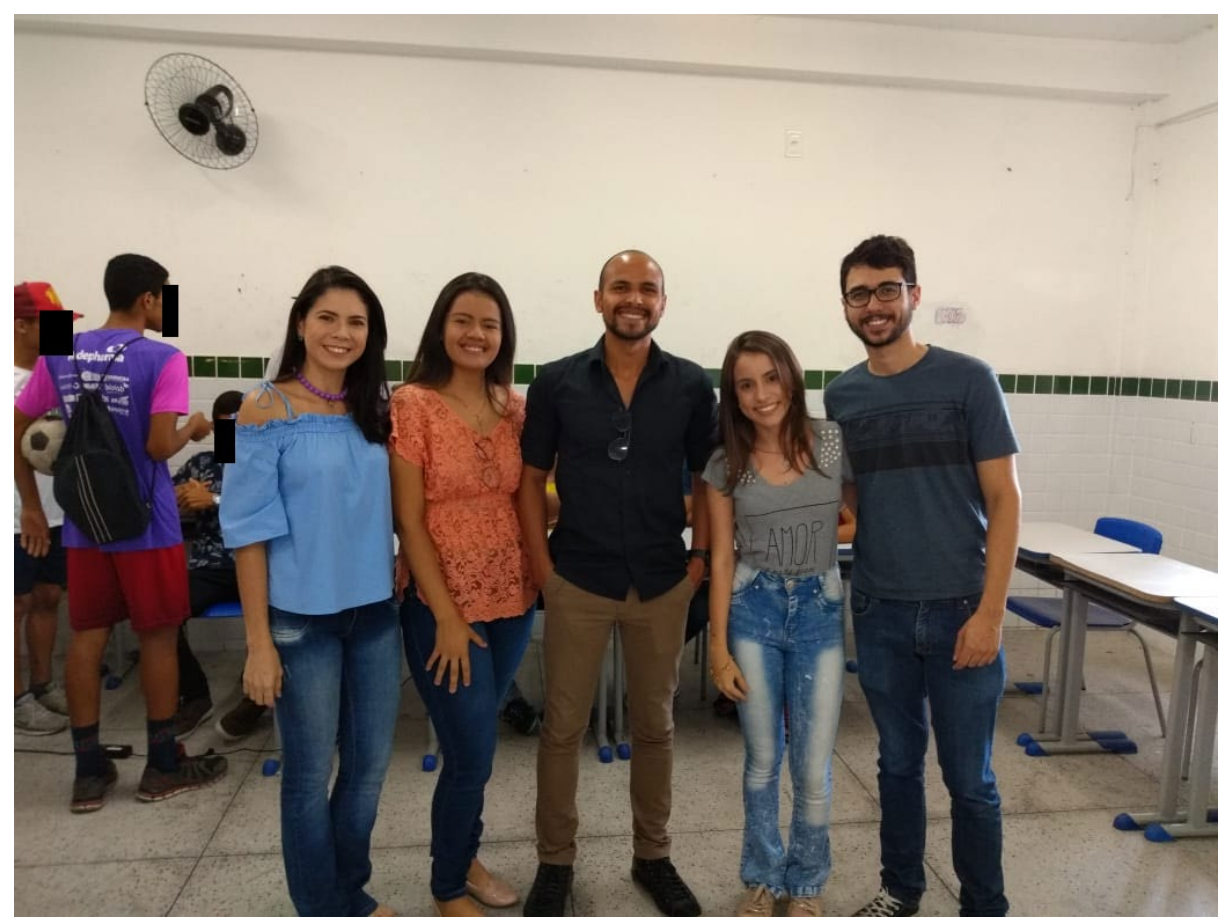

CRÉditos: LENo ÂNGELO BARBOSA DE NORMANDO. 
Figura 11: Visita do PROFESSOR AGNALdo À MOSTRA de Projetos.

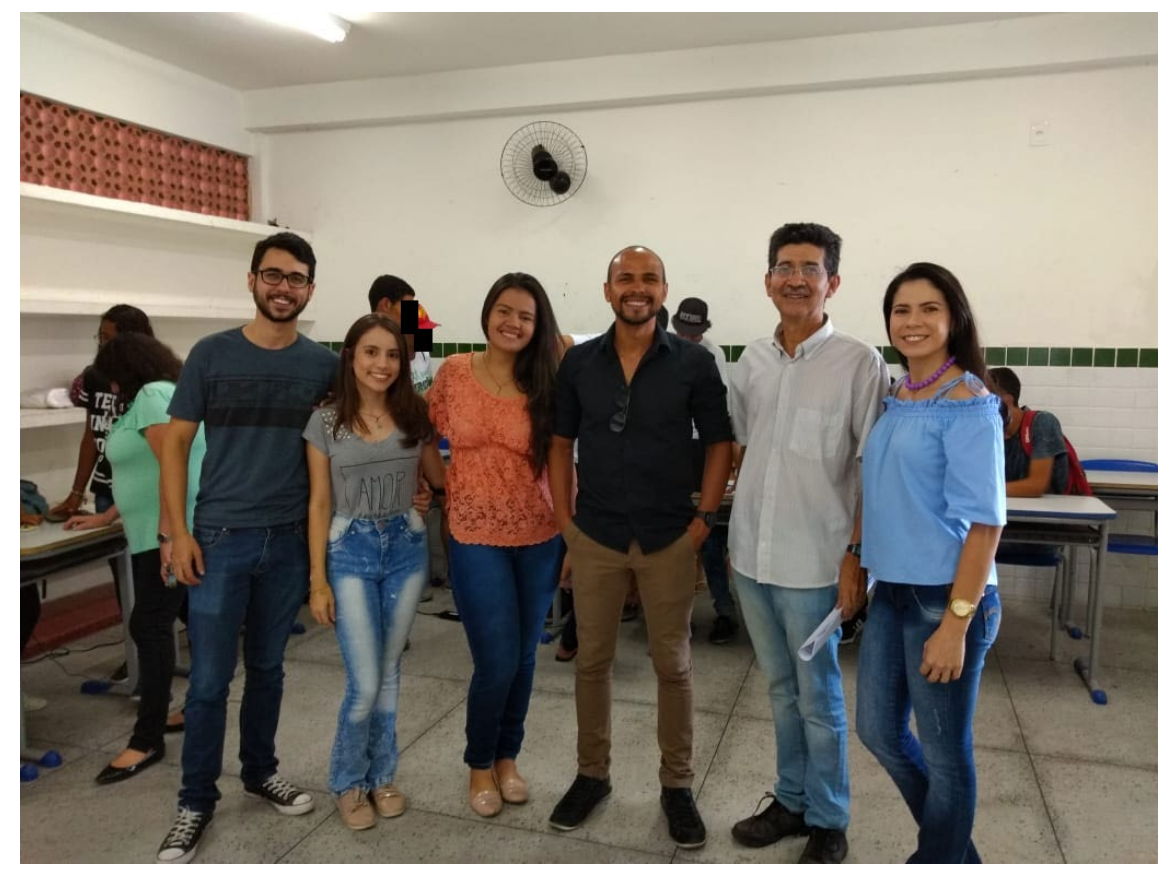

Créditos: Leno ÂNGelo BARBosa de Normando.

FIGURA 12: INTEGRANTES DO GRUPO DO PROJETO SENSOR DE RÉ PARA AUTOMÓVEIS.

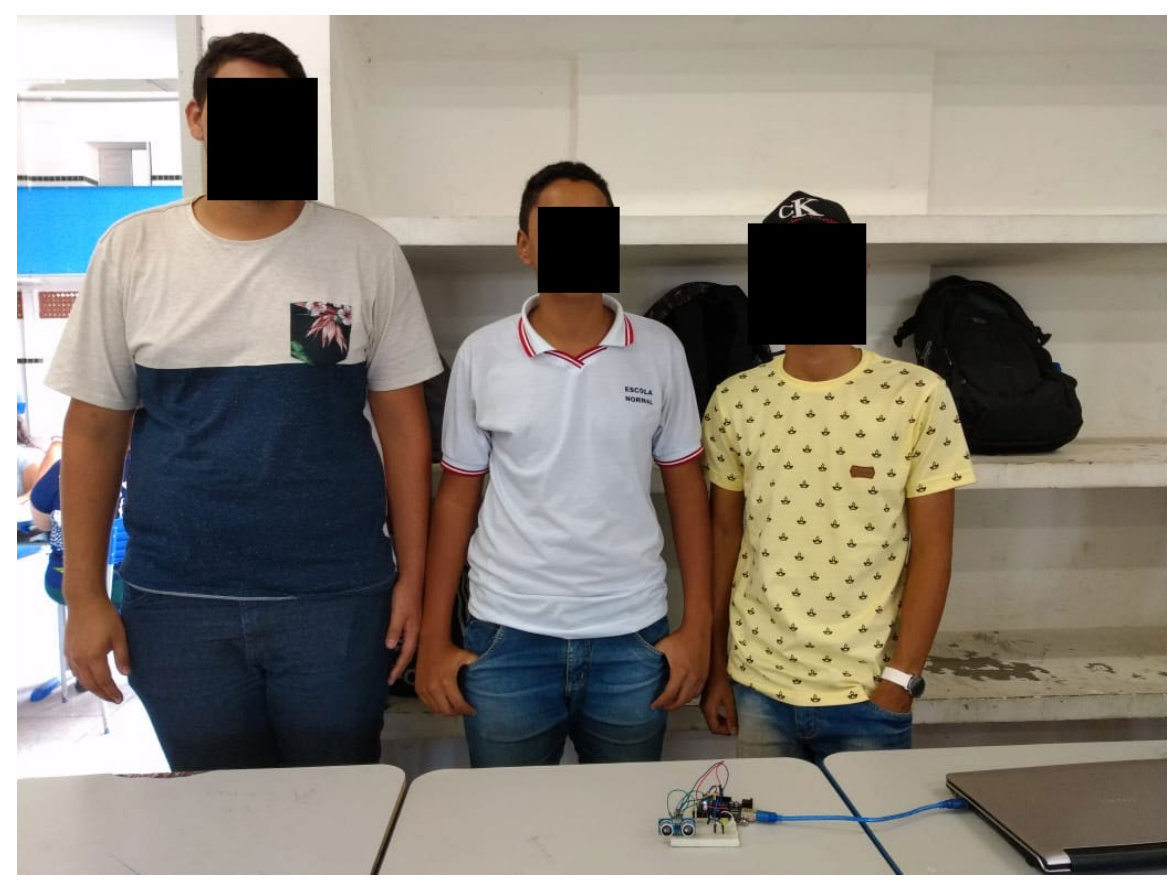

CRÉditos: Joyce VANesSa MoRaIS Rodricues. 
FIGURA 13: INTEGRANTES DO GRUPO DO PROJETO INDICADOR DE LUMINOSIDADE.

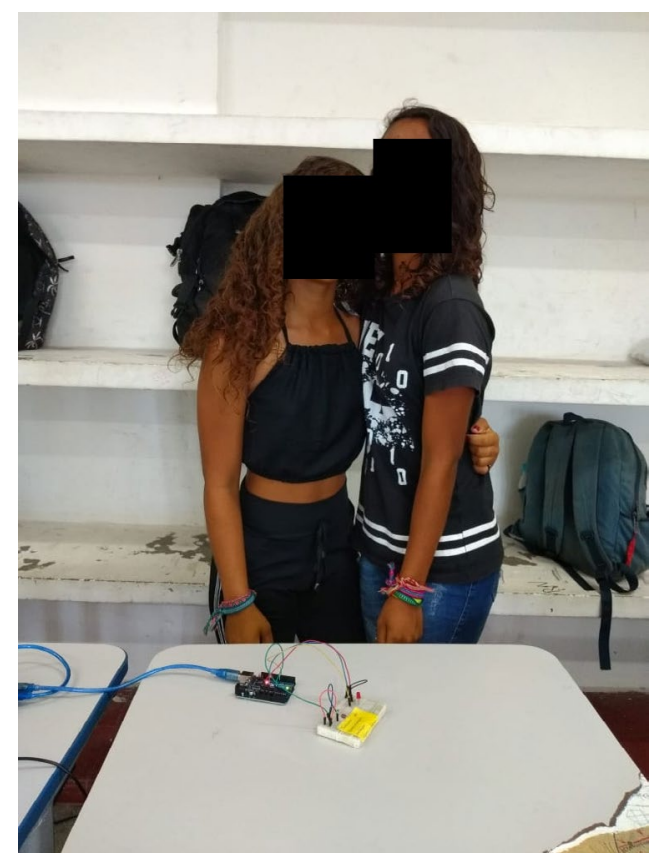

CRÉditos: Joyce VANESSA MoRaIS RodRiGues.

FIGURA 14: INTEGRANTES DO GRUPO DO PROJETO SEMÁFORO.

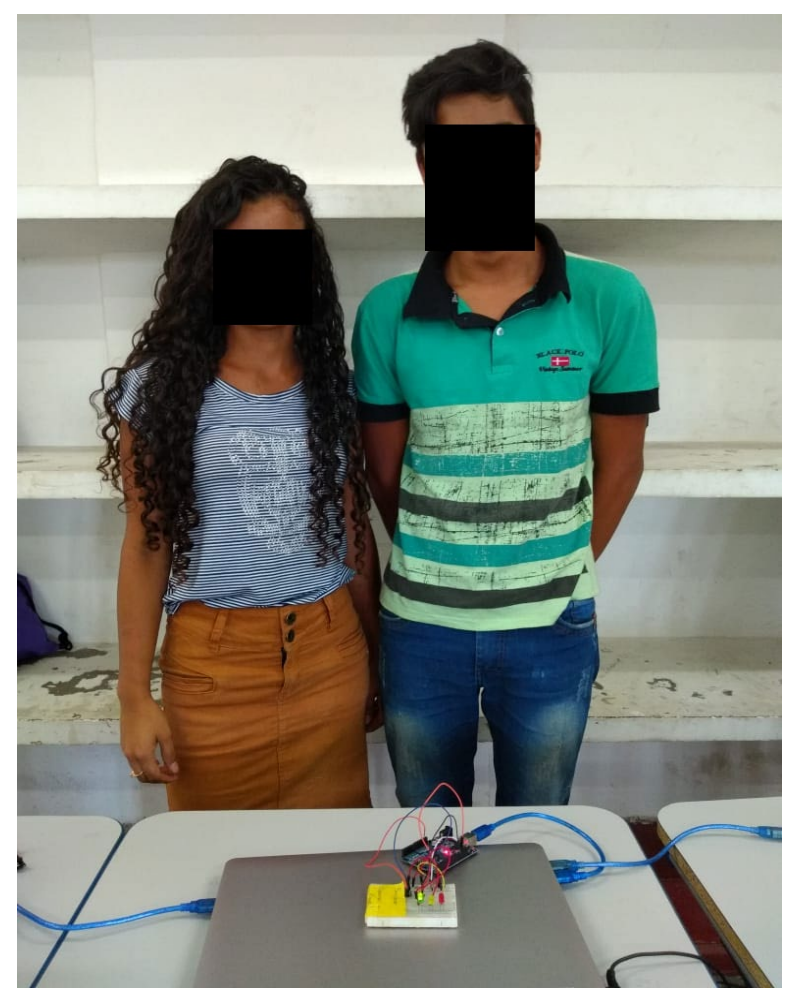

CRÉDITOS: JOYCE VANESSA MORAIS RODRIGUES. 
FIGURA 15: INTEG RANTES DO GRUPO DO PROJETO PIANO.

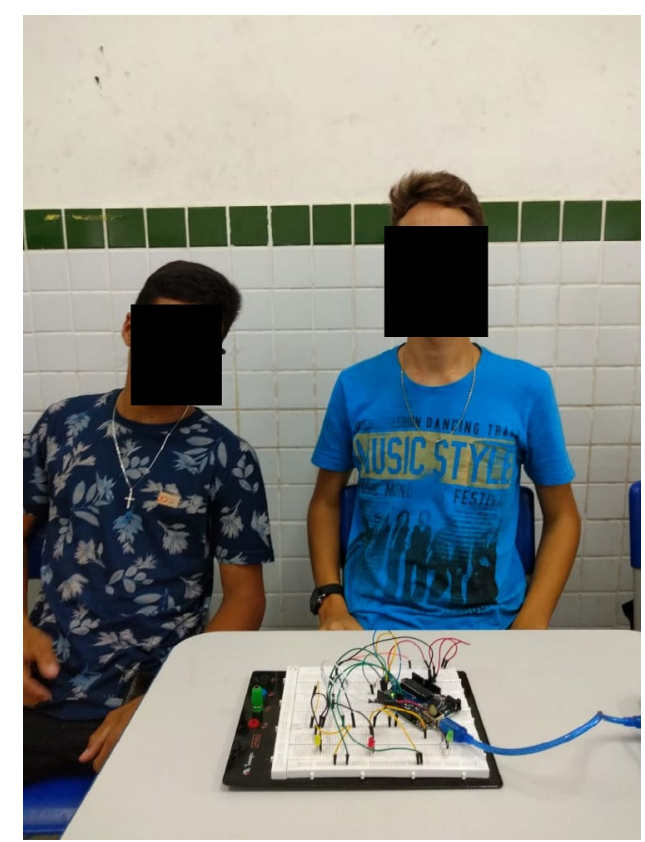

CRÉditos: Joyce VANESSA Morais Rodrigues.

FIGURA 16: INTEGRANTES DO GRUPO DO PROJETO INTERRUPTOR.

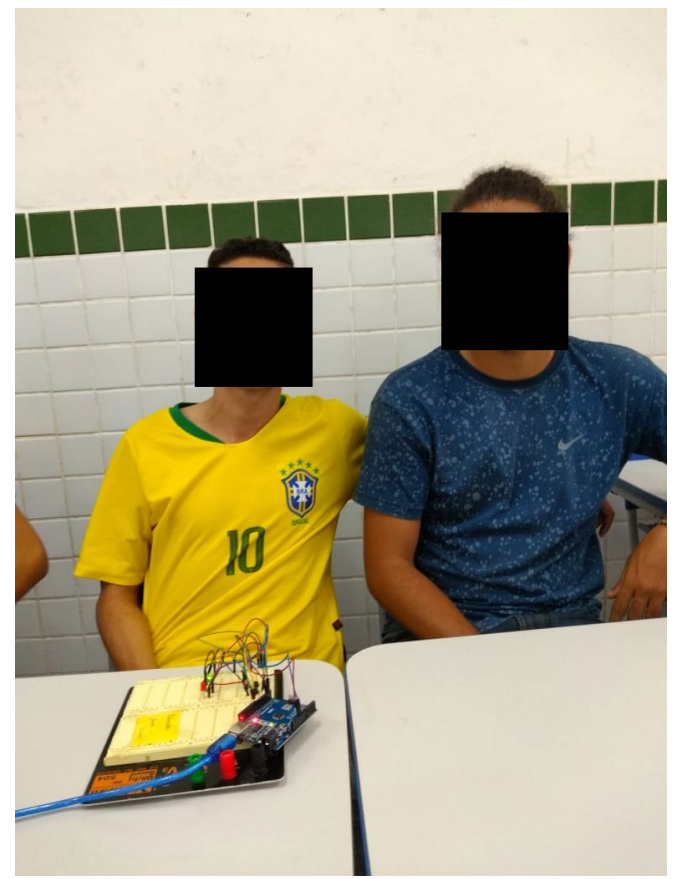

CRÉditos: JoYce VANESSA MORAIS RodriGUes. 


\section{RESULTADOS}

O Projeto Desenvolvimento de Competências na Área de Tecnologia para Estudantes de Ensino Médio foi uma experiência transformadora na vida estudantil e pessoal de cada um dos alunos de graduação envolvidos, na qual tiveram uma experiência extremamente positiva no projeto. Todos desenvolveram habilidades pessoais que poderão usar ao longo da sua vida pessoal e profissional. Dentre essas habilidades podemos citar o trabalho em grupo, oratória, criatividade, resolução de problemas, tomada de decisão, flexibilidade cognitiva, gestão de pessoas e de projetos e orientação para servir.

Pode-se constatar, que todos os objetivos propostos no projeto foram atingidos, tendo por base os feedbacks feitos após cada curso ministrado. Enfatiza-se aqui, que o índice de satisfação foi elevado principalmente para os cursos de eletrônica e programação. É importante ressaltar que, ao concluirmos o projeto, como resultado final, foi realizado um workshop, com apresentações de projetos construídos pelos próprios alunos de ensino médio. Deve-se destacar, também, a apresentação do trabalho que será feita pelos selecionados (bolsistas e voluntários) neste projeto, no Encontro de Extensão Universitária da UFCG, que será realizado na cidade de Pombal-PB.

A conexão estabelecida entre os alunos de ensino médio com os alunos de graduação foi importante para que os bolsistas e voluntários pudessem compartilhar, além do conteúdo que já adquiriram como estudantes de Engenharia Elétrica, experiências pessoais como a ansiedade antes do vestibular e a realidade da Universidade. Essa parte da experiência foi importante para os graduandos, pois mostrou que todos podem ensinar muito mais do que imaginam.

A partir dessa relação estabelecida entre todos, pôde ser observado um envolvimento crescente dos alunos com o projeto. Muitos, após o início do projeto, relataram uma melhora nas notas de física e matemática. Além disso, alguns demonstraram interesse por cursos na área de tecnologia, principalmente Ciência da Computação e Engenharia Elétrica.

Ao fim do projeto, foram gravados vídeos com depoimentos de cada aluno sobre sua experiência no projeto e a grande maioria dos participantes que permaneceram elogiaram o projeto, discutiram sobre as competências técnicas na área de tecnologia e comportamentais, na tomada de decisão, resiliência e criatividade que desenvolveram, e demonstraram interesse em seguir a área de tecnologia. 
Sendo assim, pode ser afirmado que a experiência pessoal e também estudantil dos alunos de ensino médio envolvidos no projeto foi extremamente positiva. Todos os alunos de graduação (bolsistas e voluntários) envolvidos no projeto em questão apresentaram grande interesse com as atividades ao longo do projeto. Desde a parte de planejamento à execução das atividades. Foi possível observar um grupo trabalhando em sintonia e com um senso de responsabilidade coletiva exemplar.

O envolvimento e organização do grupo podem ser notados, por exemplo, nas reuniões, com ou sem o orientador, e no compromisso da realização de todas as etapas estabelecidas no planejamento do projeto, mesmo com algumas adversidades encontradas ao longo do projeto, como a saída de membros, aquisição de novos componentes, reformulação do planejamento de aulas devido a feriados e mudança na logística de transporte que alterou o orçamento de transporte. Além disso, a distribuição de atividades foi muito bem estabelecida desde o início do projeto, na apresentação do projeto aos alunos e divisão inicial das duplas ministrantes das aulas, o que facilitou a execução das atividades e participação de todo alunato.

\section{CONSIDERAÇÕES FINAIS}

O Projeto de Desenvolvimento de Competências na Área de Tecnologia em Estudantes de Ensino Médio foi uma experiência diferenciada na vida de todos os envolvidos. Os alunos de ensino médio e graduação, assim como também alguns professores, tiveram uma vivência positiva com assuntos relacionados a tecnologia e ao desenvolvimento pessoal/profissional. Esse projeto foi capaz de ressignificar, para todos os envolvidos, a construção do conhecimento na área de tecnologia e a suas aplicações totalmente acessíveis (MENEGON; GOUVEIA, 2013).

A modificação que pode ser observado nos alunos, desde a construção do conhecimento até na atitude positiva de cada um ao se encerrar as atividades do projeto, reafirma a importância do papel da extensão universitária (MENEGON; GOUVEIA, 2013; MARTINS, 2008). 


\section{REFERÊNCIAS}

ARCOVERDE, L. Proposta quer flexibilizar a formação de engenheiro. Revista Valor Econômico. São Paulo, 2018.

ALVARENGA, C. F., SALES, A. P. Desafios do Ensino Superior para Estudantes de Escola Pública: Um estudo na UFLA. Revista Pensamento Contemporâneo em Administração. Minas Gerais, 2012.

IPEA. Instituto de Pesquisa Econômica Aplicada. Pesquisa do IPEA constatam escassez de engenheiros. 2018. Disponível em: http://www.ipea.gov.br/portal/index. php?option=com_content\&view=article\&id=20486. Acesso em: 4 dez. 2018.

LOVATTI, B. G., VIEIRA, L. S., MARQUES, K., SCOLFORO, M. A. A programação no Ensino Básico: Formando alunos para a Sociedade Tecnológica. Revista Ambiente Acadêmico, v. 3. Vitória, 2017.

MCROBERTS, M. Arduino Básico. Novatec, 2011.

MENEGON, R. R., GOUVEIA, S. A. Projetos de Extensão: Um diferencial para o processo de formação. Universidade Estadual Paulista (UNESP). Presidente Prudente, 2013. MARTINS, E. Extensão como componente curricular: oportunidade de formação integral e de solidariedade. Goiânia, Julho de 2008. Base de dados do Scielo. Ciência e Cognição. Disponível em: http://cienciasecognicao.org/. Acesso em: 14/12/2018.

OLIVEIRA, I. B., SILVA, J. F. Relatório Final do DECATEC 2017. Campina Grande, 2017.

RAZAVI, B. Fundamentos de Microeletrônica. Rio de Janeiro: LTC, 2010.

SEDRA, A. S.; SMITH, K. C. Microeletrônica. 5 ed. São Paulo: Pearson, 2007. 